\title{
Sight for Sore Eyes: Cuba's Vision Restoration Program
}

\section{By Conner Gorry}

If you're reading this, you're not one of the 121 million people worldwide[1] suffering from blindness or vision loss caused by cataracts, diabetic retinopathy and other reversible or preventable conditions causing visual impairment. Or perhaps you've benefited from vision restoration surgery. If so, you know how straightforward many of these procedures are when performed by trained specialists, using the latest technology and techniques.

Unfortunately, many of the millions needing these simple surgeries - over $90 \%$ of them in developing countries[1] - can't afford them. In Latin America and the Caribbean alone, an estimated 2.8 million people are blind and 11.2 million visually impaired,[2] most of them poor and either very young or very old. Two-thirds of these conditions are reversible, with procedures like cataract surgery (see Box: Vision in Latin America \& the Caribbean).

These astounding figures prompted Cuba to develop a regional partnership for vision restoration known as Operación Milagro (Operation Miracle). The goal: reverse blindness and vision loss for 6 million people in Latin America and the Caribbean by 2016.

Launched in 2004, Operación Milagro began as a bilateral program between Cuba and Venezuela when it became evident to Cuban teachers working in Venezuela's literacy campaign that

\section{Vision in Latin America \& the Caribbean}

- For every one million persons in Latin America and the Caribbean, 5,000 are blind, with visual acuity $<20 / 400$, or $<3 / 60$, in the best eye) and 20,000 are visually impaired, with visual acuity $<20 / 70$, or $<6 / 18$, in the best eye, translating into $2,790,000$ blind and 11,160,000 visually impaired in the region.

- An estimated 6 million people suffer low vision, with visual acuity $<6 / 18$ but $\geq 3 / 60$, after treatment or standard refractive correction.

- At least two-thirds of blindness is attributable to treatable conditions. Nearly $60 \%$ of blindness and visual impairment is due to unoperated cataracts. Other important causes are glaucoma, diabetic retinopathy, and childhood blindness. Uncorrected refractive errors are an important cause of visual impairment.

- The number of ophthalmologists per million in the region's richest countries is nine times greater than in the poorest countries.

- Affordability limits access to eye services for the poor in almost all countries in Latin America and the Caribbean.

- The number of cataract operations performed per year, per million (cataract surgical rate) in developed countries is usually between 4,000 and 6,000; in Latin America, this rate varies according to the social and economic development of the countries and ranges from 500 to 2,000, with the lowest rates in the poorest regions.

Sources: Health in the Americas 2007, Pan American Health Organization (PAHO), Washington DC, 2007. Volume 1, page 141.

Silva JC, Bronwyn Bateman J, Contreras, F. Eye Disease and Care in Latin America and the Caribbean. Surv Ophthalmol. 2002;47(3):267-274. many prospective students couldn't see, thereby remaining beyond the program's reach.[3] Operación Milagro was launched as a result of these findings.

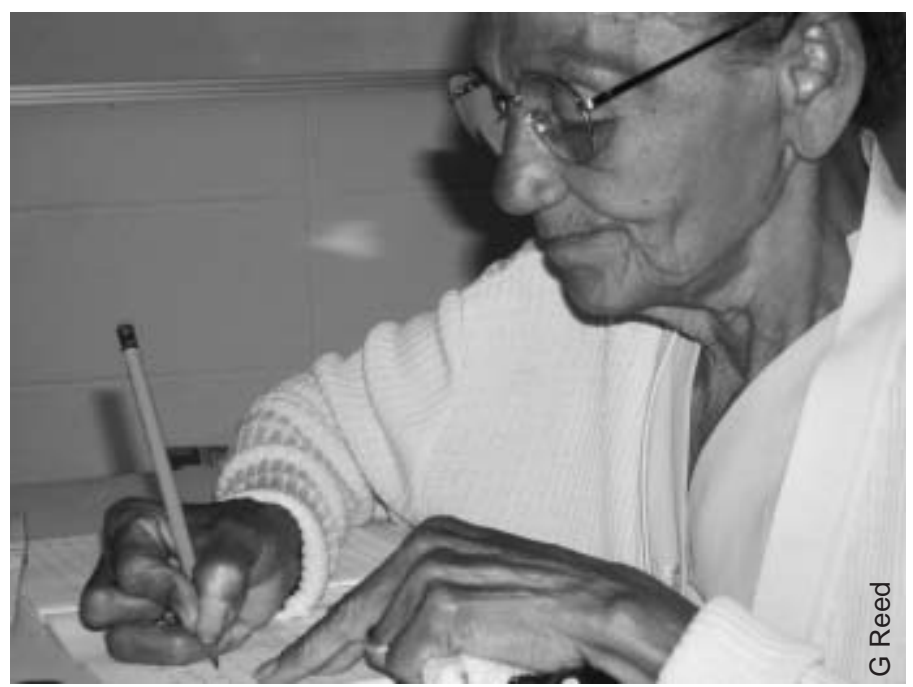

Literacy class in Venezuela: corrected vision a must for seniors

Originally conceived to operate on 5,000 poor Latin Americans a year, four years later the program is averaging 5,000 surgeries per month. As of March 13, 2008, 1,035,566 people from 32 countries have had their vision improved or fully restored[4]. The program is free for patients - not only from Cuba, Venezuela, and other Latin American and Caribbean countries, but now from Africa and China as well (for details, see Box: Fast Figures: Operación Milagro).

The program's tenets mirror those of Cuba's health system and its international cooperation agreements in health:

- $\quad$ Contribute to equitable delivery of quality care.

- Prioritize training human resources to effectively deliver this care - including nurses, technicians, and support staff - both in Cuba and recipient countries.

- Implement technology transfer to recipient countries' public health systems, to encourage local sustainability.

\section{Phase 1: Venezuela}

The first Operación Milagro surgeries were performed in July 2004 within the framework of the Bolivarian Alternative for the Americas accords (ALBA), in which the Cuban and later Venezuelan government covered the cost and human resource burden of the program. Patients were identified in active screenings carried out by Cuban specialists in some of Venezuela's poorest and most remote regions.

Once identified, patients were flown to Havana with a family member, received surgical treatment at the Ramón Pando Ferrer Ophthalmology Institute and accommodated at a hotel for the immediate recovery and follow-up period. In addition to the surgery and related medicines, all transportation, food and lodging for both the 


\section{International Cooperation Report}

patient and their escort were free of charge. By the end of 2004, 14,000 Venezuelans had their sight restored in this first phase of the program.[5]

By 2006, the rhythm had increased substantially: from January 1 through February 7, 41 Operación Milagro round-trip flights were organized from the newly-remodeled Barcelona Airport in eastern Venezuela's Anzoategui State, transporting 3,074 patients in the five-week period.[6] The airport rebuilding, plus the logistics of the operation, were undertaken by the Refinación Oriente headquarters of the Venezuelan state oil company, PDVSA. "We invest about $13 \%$ of our total budget in social programs like this, so part of our profits go into health," Refinación Oriente General Manager Fernando Padrón told MEDICC Review at the time. "PDVSA is an oil company: we've always had the capability to manage this kind of project, but before we were just a money-making machine for Venezuela. We really weren't conscious that some $80 \%$ of Venezuelans were poor. Now we feel a responsibility. I'm an engineer and l've been in the oil industry for 25 years, but l've never experienced anything like this: people leave this airport blind; and when they return they can see."

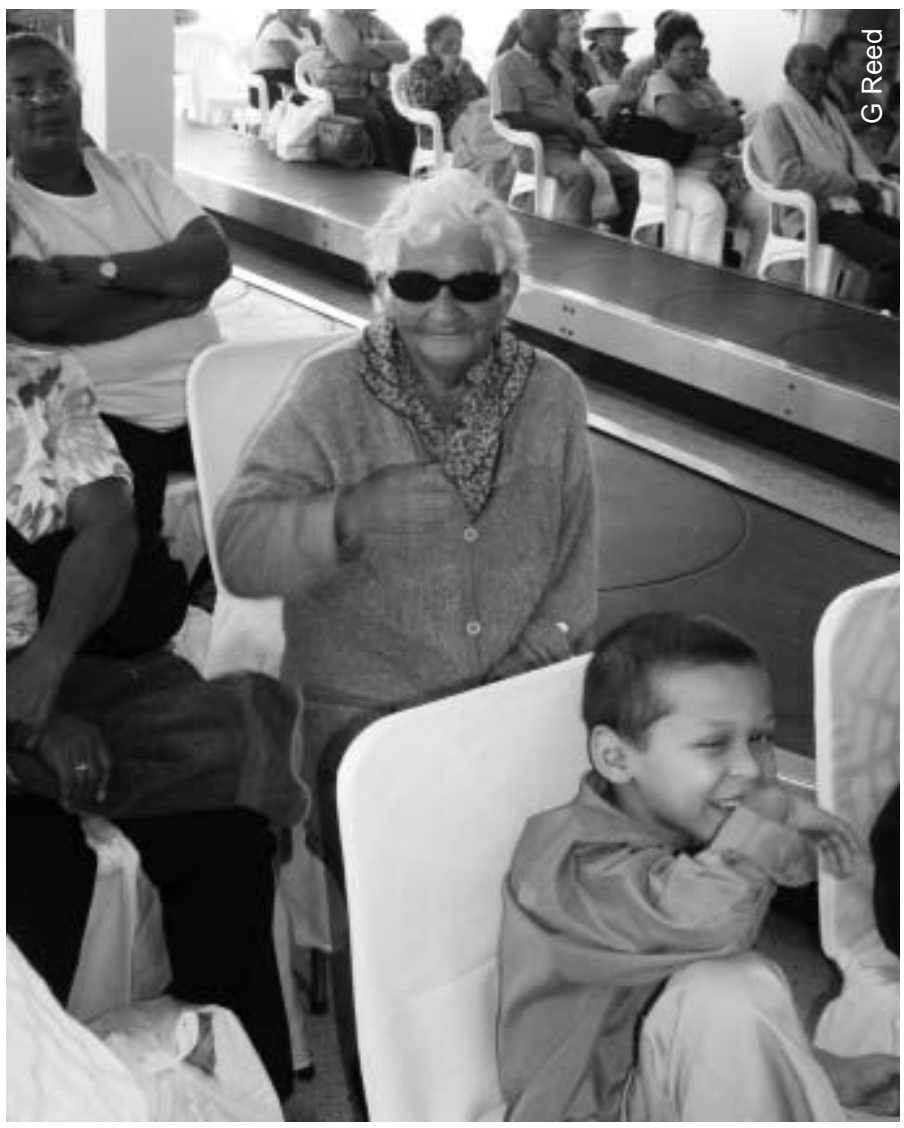

Patients at the Barcelona Airport waiting for flight to Cuba

\section{Phase 2: The Caribbean \& Latin America}

Operación Milagro was extended throughout the region, as governments analyzed the program and approached Cuba to participate. The second phase began in 2005, when Caribbean countries including Jamaica, Dominica and St Lucia joined. The scope of Operación Milagro has also developed apace, as more conditions are added to the list of surgeries available, which now

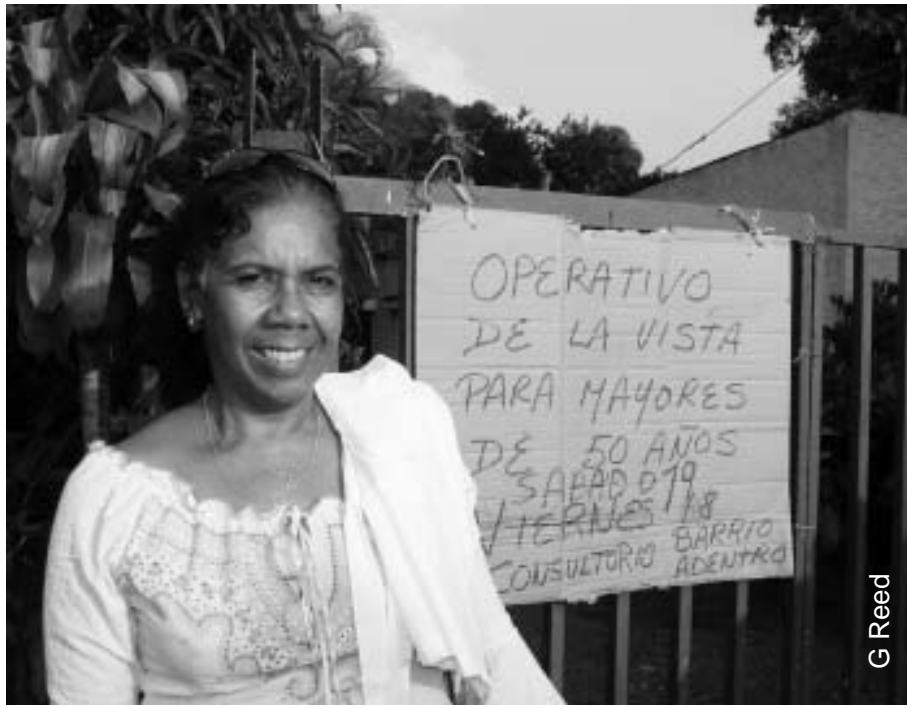

Cuban doctor in Caracas: her sign announces Operación Milagro office hours

include cataracts, pterygium, diabetic retinopathy, retinopathy of prematurity, glaucoma, ptosis, strabismus, nyctalopia (night blindness), and retinitis pigmentosa. Moreover, Cuba's biotechnology industry continues to develop and produce medications used in the procedures.

Results have been highly positive, according to Dr Juan Raúl Hernández, Technical Vice Director and ophthalmologist at the Pando Ferrer Ophthalmology Institute, who notes complication rates of less than $1 \%$. "And the main complications, like post-operative capsule rupture, are easy to resolve and treat," he says. "It's exceptionally rare for us to see an infection after surgery for instance." This is particularly notable, added Dr Hernández, since patients qualifying for Operación Milagro (poor and in poor health generally) often present the most difficult cases, suffering from "40 years of hard rock cataracts or ocular trauma."

\section{Phase 3: Sustainability \& Challenges}

The program entered its third phase at the end of 2005 with the inauguration of ophthalmology screening and surgery centers in participating countries. Staffed by Cuban specialists initially, 47 of these local centers equipped with 85 surgical stations have been established in 11 countries. The goal is to transfer the technology and know-how to host countries' public health systems to ensure sustainability. Receiving treatment from a local specialist closer to home is not only more comfortable for patients, it frees up resources for other domestic and international health initiatives previously devoted to treating these patients in Cuba.

With the triumphs, however, have also come challenges. Early on, Cuban cataract patients were not included in the program, and their waiting times for surgery began to lengthen. The solution was to include them in Operación Milagro, streamlining the process. By the end of 2007 "cataract blindness statistically no longer existed in Cuba," according to Dr Marcelino Río, Director of the Ophthalmology Institute, and over 150,000 Cubans had undergone cataract surgery. In another development inspired by Operación Milagro, 557 corneal transplants were conducted in 2007 , the most in one year in the country's history. 


\section{International Cooperation Report}

\section{Fast Figures: Operación Milagro}

As of March 13, 2008, the vision restoration program included:

- Patients operated on: $1,035,566$

- Participant countries: 32

- Patients from:

Latin America (15 countries): 835,824

The Caribbean (15 countries): 42,916

Cuba: 151,805

Mali: 5,021

- Foreign patients operated on in Cuba: 261,143

- Patients operated on at in-country centers: 622,618

- In-country ophthalmology centers donated by Cuba: 47

Bolivia (15); Ecuador (3); Guatemala (2); Haiti (2);

Honduras (3); Mali (1); Nicaragua (1); Panama (1);

Paraguay (1); Uruguay (1); Venezuela (17)

- High-tech surgical stations donated by Cuba: 85

- Countries with local ophthalmology centers: 11

Source: Ministry of Foreign Relations (MINREX), Havana.

www.cubacoop.com/cubacoop/misionmiligros.htm

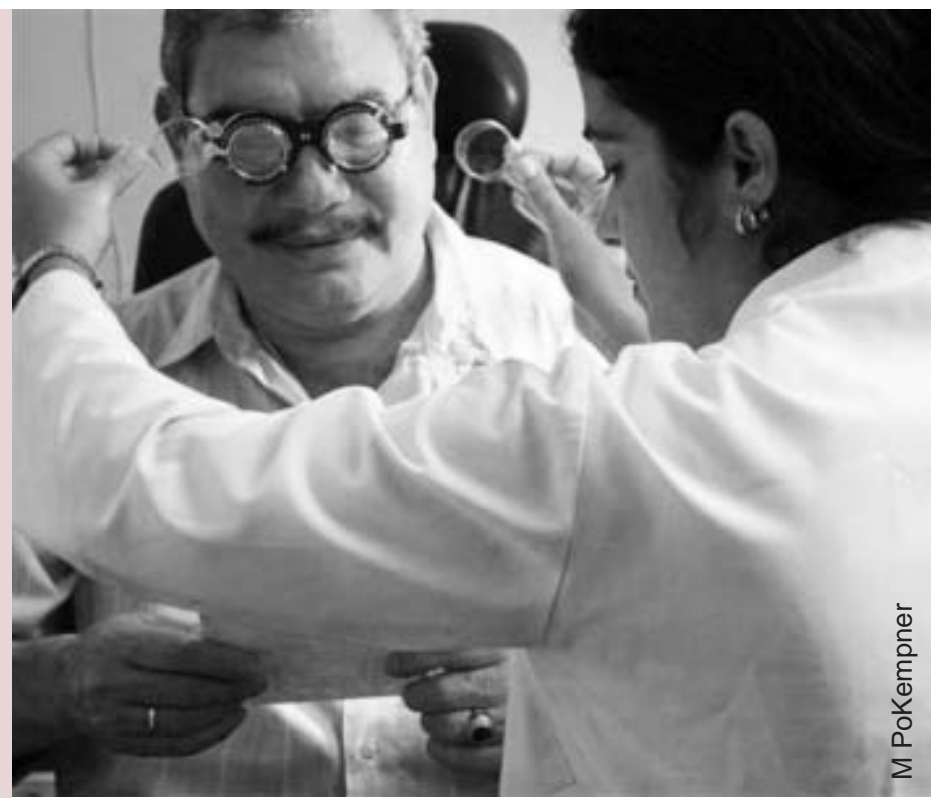

Protests by ophthalmology societies have also erupted in countries where Operación Milagro has had the greatest impact. Dr Miguel Zylberglajt, president of the Uruguayan Society of Ophthalmologists summed up their position when he said "the [Cuban] presence here is unnecessary since they didn't bring any equipment that wasn't already available in Uruguay. Not [available] in the public health system, but in private clinics, yes."[7]

But Dr Juan Carlos Silva of the Johns Hopkins School of Public Health addresses the underlying human resource dilemma in his seminal article on vision in Latin America and the Caribbean. While noting that the 19,000 ophthalmologists in the region should be sufficient to meet all needs, he found that "unfortunately, most ophthalmologists work in private practice, limit their services to patients who can afford it, and are located in the wealthier neigh- borhoods of urban centers, reducing availability and accessibility of services to a large proportion of the population."[8]

Clearly, the conflict between health care for those that can afford it and equitable and universal care for improved population health overall, particularly for the region's rural poor, comes to a head wherever the program works to restore sight for free. In some cases, like El Salvador, Operación Milagro has served as an example, spurring ophthalmology societies to push for a national cataract program where before there was none.

Whether the 6 million mark will be reached by 2016 remains to be seen, but for the over 1 million recipients of free vision restoration surgeries thus far, modern medicine is indeed miraculous. 1 -

\section{References \& Notes}

1. Note: this statistic does not include vision loss due to refractive errors. World Health Organization. Global Initiative for the Elimination of Avoidable Blindness: Action plan 2006-2011. Geneva; 2007

2. Pan American Health Organization (PAHO). Health in the Americas 2007, Volume 1. Washington DC: PAHO; 2007.

3. Some 1.4 million Venezuelans learned to read and write with the Cuban-designed Yo Sí Puedo (Yes, I Can) program, cited for its efficacy by UNESCO. The program is currently being implemented in several countries around the region.

4. Cuba Coopera [homepage on the Internet]. Havana: MINREX; 2008 [updated 2008 Mar 17; cited 2008 Mar 27]. Available from: www.cubacoop.com/cubacoop/misionmilagros.htm.
5. Interview with Dr Marcelino Río by the author, 30 Nov 2007.

6. Refinación Oriente. Resumen de Actividades en Aeropuerto Barcelona, Misión Milagro. Acumulado del 01-01-06 al 07-02-06. Photocopy of original obtained from Fernando Padrón, General Manager, Refinación Oriente, 5 Feb 2006.

7. AFP. Oftalmólogos uruguayos rechazan ejercicio de médicos cubanos en Montevideo. Nov 302007 [cited Mar 8 2008]. Available from: http://afp. google.com/article/ALeqM5jkazyAPflE9odrYzoOX7PTkIM-fw. Translated by the author.

8. Silva JC, Bronwyn Bateman J, Contreras F. Eye Disease and Care in Latin America and the Caribbean. Surv Ophthalmol. 2002;47(3):267-274. 